\title{
NOTES ON THE LINES 93-94 OF THE HOMERIC HYMN TO APHRODITE
}

\author{
Ichiro Taida
}

\begin{abstract}
In the lines 93-94 of the Homeric Hymn to Aphrodite, five goddesses (Artemis, Leto, Aphrodite, Themis and Athene) are enumerated. The reason why the poet of the hymn arranged them in that order has not been made clear yet. The purpose of this paper is to find a solution to this question.
\end{abstract}

To reaffirm his sovereignty over Aphrodite, Zeus makes her fall in love with a mortal man, the Trojan prince Anchises. Aphrodite visits him in the hut on the mountain Ida, disguised as a pure maiden. He is surprised at her beauty and seized by love. Anchises casts his speech of welcome and, to ascertain her identity, he offers her seven choices, Artemis, Leto, Aphrodite, Themis, Athene, Charis and Nymph. ${ }^{1}$

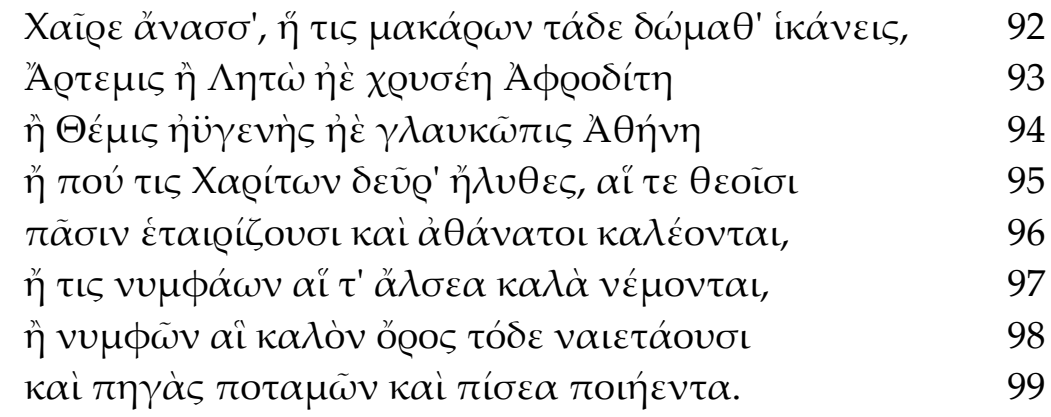

There is a gap between 93-94 and 95-99 in this list. In the lines 93-94 only the names and epithets of the five goddesses are enumerated. On the other hand, in the lines 95-99 Charis and Nymph are described in detail by using relative clauses. It is appropriate that the descriptions of Charis and Nymph, who are often subordinate to a goddess, are given after the five goddesses in the list. However, it is not clear why the poet of the hymn arranged the five goddesses in this order. Walcot has written: "The list artfully conceals the true answer, Aphrodite, between two pairs of alternative identifications, each of which includes a goddess, Artemis in the one case and Athene in the other, previously singled out as a virgin goddess sharply contrasting with the sex-ridden Aphrodite (vv. 8-20)."2 However, whether the poet intentionally arranged the goddesses in this order to aim at the effect is not very certain. The purpose of this paper is making the grounds for choosing this order of the five goddesses clear.

If we just arrange any five goddesses, we can choose one among 120 orders.

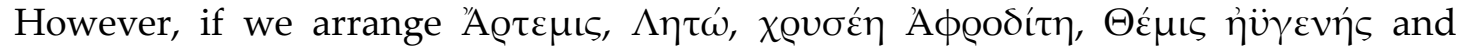
$\gamma \lambda \alpha v \kappa \tilde{\omega} \pi \iota \varsigma$ A $\theta \eta \dot{v} \eta$ in two hexameter lines (93-94), connecting each one with $\eta$ or $\eta \dot{\varepsilon}$,

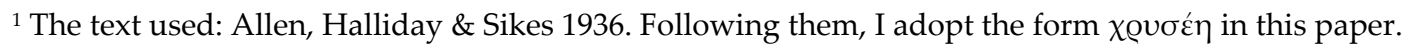

2 Walcot 1991: 145. 


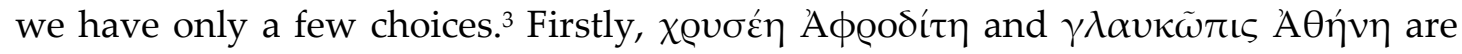
always in the second half of the line in Epic. ${ }^{4}$ In 93-94 too, each of them must be in

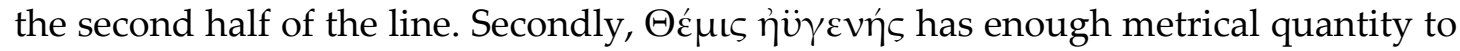

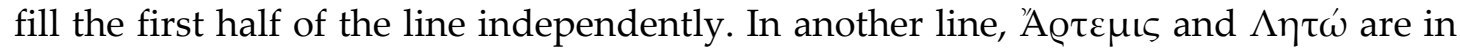

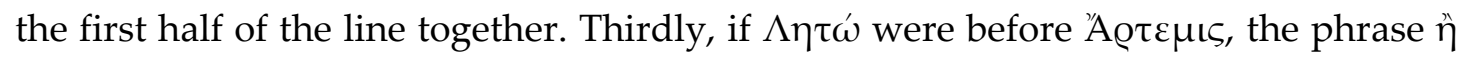

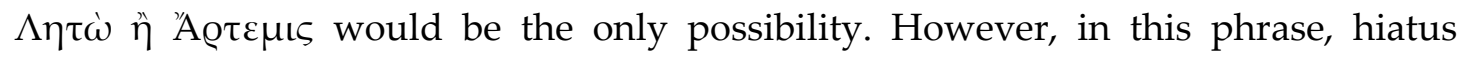
would occur between $-\dot{\omega}$ and $\eta$, and $\eta$ and 'A-. Moreover, there would be no caesura

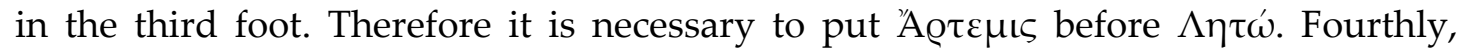

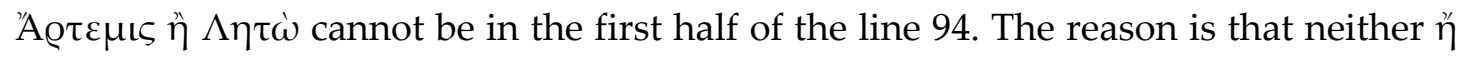

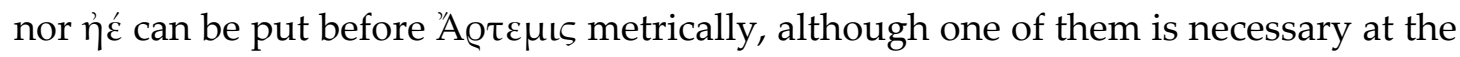

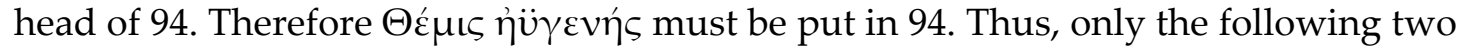
possibilities remain:

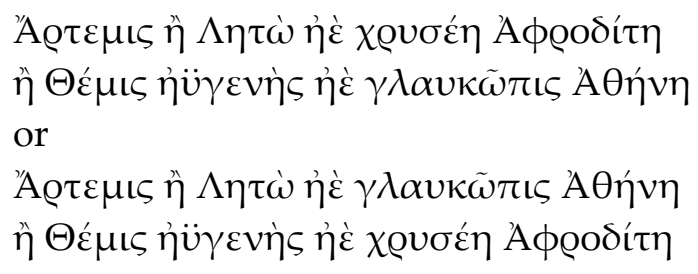

A definitive reason to choose the former can not be immediately understood. However, when the poet of the hymn composed the line 93, he must have found a

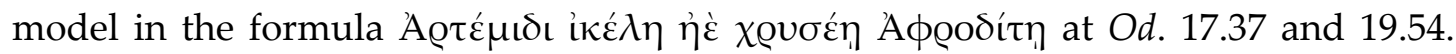
The reason why we should think this formula is a model of 93 is the coincidence of the words. ${ }^{5}$ Moreover, this formula is used in the scenes that look like the one described here: in expressing the beauty of Penelope. In both Od. 17.37 and 19.54 she is about to appear in front of others. Here too, a beautiful girl appears in front of Anchises. Following this Homeric model, the poet of the hymn must have arranged

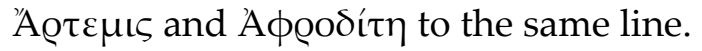

\section{Dr. Ichiro Taida}

Department of Applied Japanese, I-Shou University, Taiwan

E-mail:ictmh111@yahoo.co.jp

\section{References}

Allen, T. W.; Halliday, W. R.; Sikes, E. E. (edd.) (1936) The Homeric Hymns. 2nd edition. Oxford: Clarendon Press.

Walcot, Peter (1991) 'The Homeric Hymn to Aphrodite: a literary appraisal.' - GER 38.2, 137-155.

\footnotetext{
${ }^{3}$ Certainly, nothing prevents the poet from choosing other epithets and different frame. This question will be discussed elsewhere.

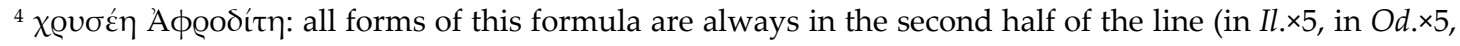

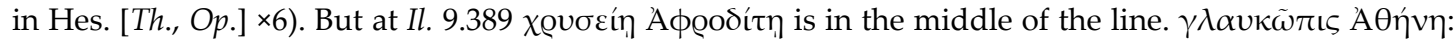
this nominative is always in the second half of the line (in Il. $\times 28$, in Od. $\times 50$, in Hes. [Th., Op., Sc.] $\times 6$ ).

${ }^{5} \mathrm{Od}$. 17.37 and 19.54 are the only examples in Homer, in which Artemis and Aphrodite are in the same line.
} 